\title{
A LEITURA COMPARTILHADA EM SALA DE APOIO
}

\author{
Cristiane Malinoski Pianaro Angelo* \\ Universidade Estadual do Centro-Oeste (UNICENTRO), Irati - PR, Brasil \\ Renilson José Menegassi** \\ Universidade Estadual de Maringá (UEM), Maringá - PR, Brasil
}

RESUMO: Neste artigo, aborda-se a leitura compartilhada na prática docente com alunos de Sala de Apoio à Aprendizagem de Língua Portuguesa (SAALP) $-6^{\circ}$ ano do Ensino Fundamental. Tomando-se o conceito de leitura réplica, derivada das discussões acerca dos trabalhos do Círculo de Bakhtin, buscou-se orientar a prática de um professor de SAALP na abordagem das tarefas de leitura compartilhada em sala de aula. A coleta de dados deu-se anterior e posteriormente a intervenções teórico-metodológicas de modo colaborativo com o docente, propiciandolhe aportes teóricos e discussões orientadas a respeito dos processos e das estratégias de leitura. Os resultados demonstram que, por meio das tarefas de leitura compartilhada, o trabalho pedagógico em SAALP tornase mais significativo, auxiliando os alunos na superação das dificuldades de aprendizagem em leitura e no seu desenvolvimento como leitor que toma uma posição em relação ao enunciado do outro, manifestando uma réplica. Palavras-chave: Leitura compartilhada. Sala de Apoio à Aprendizagem. Formação docente continuada.

\section{THE SHARED READING MODEL IN SUPPORT CLASSROOM}

ABSTRACT: It is discussed, in this paper, the shared reading model in teacher's practice in a Support Classroom for Portuguese Language Learning (SAAPL, in Portuguese) $-6^{\text {th }}$ grade of basic schooling. Adopting the concept of reading replica, derived from discussions about the works from Bakhtin Circle, it was made an attempt to guide the practice of a SAALP's teacher in the approach of shared reading in classroom. Data collection was done before and after theoretical-methodological intervention in a collaborative way with the teacher, offering him a theoretical basis and guided discussions concerning reading processes and strategies. The results show that, by means of shared reading tasks, the pedagogical work in a SAALP becomes

http://dx.doi.org/10.1590/0102-4698148679

*Doutora em Letras pela Universidade Estadual de Maringá (UEM). Professora da Universidade Estadual do Centro-Oeste (UNICENTRO). Líder do grupo de pesquisa "Interação e ensino" da Universidade Estadual do Centro-Oeste (UNICENTRO/CNPq). E-mail: < cristiane.mpa@gmail.com>.

* * Doutor em Letras pela Universidade Estadual Júlio de Mesquita Filho (UNESP). Professor da Universidade Estadual de Maringá (UEM). Líder do Grupo de Pesquisa "Interação e Escrita" da Universidade Estadual de Maringá (UEM/CNPq). E-mail: < renilson@wnet.com.br >. 
more meaningful, helping students to overcome the difficulties related to learn how to read, as well as in their development as a reader who adopts a personal position in relation to the other's utterance, expressing a replica. Keywords: Shared reading model. Support Classroom for Learning. Continuous teacher training.

\section{CONSIDERAÇÕES INICIAIS}

O presente artigo aborda o trabalho docente com a leitura compartilhada no contexto da Sala de Apoio à Aprendizagem de Língua Portuguesa - SAALP. O programa Sala de Apoio à Aprendizagem - SAA - consiste em uma política educacional que foi instituída em 2004 pela Secretaria Estadual de Educação do Paraná SEED/PR -, com o objetivo de propiciar a efetivação e a proteção ao direito que os alunos do Ensino Fundamental têm de obter uma educação de qualidade, resolvendo ou minimizando suas dificuldades de aprendizagem e estendendo seu tempo de escolaridade. Nos termos da Resolução no 208/04 - SEED/PR (Art. 1º) (PARANÁ, 2004), que implementou o programa, a Sala de Apoio busca o "enfrentamento dos problemas relacionados ao ensino de Língua Portuguesa e Matemática e às dificuldades de aprendizagem [...] no que se refere aos conteúdos de leitura, escrita e cálculo". Assim, os alunos incluídos no programa frequentam aulas de Língua Portuguesa e/ou Matemática no contraturno, participando de atividades em prol da reversão do insucesso no aprendizado dos conteúdos dessas disciplinas.

Pesquisas que investigam as SAA demonstram que os objetivos propostos para essa política educacional não vêm sendo plenamente atingidos. Fontanini (2011), por exemplo, traz a constatação de que, nessas salas, geralmente o trabalho com a metalinguagem do ensino da língua se sobrepõe, embora os documentos que normatizam o programa enfatizem a necessidade de que o foco do trabalho esteja na abordagem da leitura e da escrita. Também, Pires, Jungbluth e Peixe (2008, p. 155) registram que há uma percepção superficial tanto no diagnóstico como nos encaminhamentos para a superação das dificuldades dos alunos da SAA; assim, "a sala de apoio é apenas um apêndice, mais uma tarefa a ser cumprida. Não inserida no trabalho como um todo, com a finalidade de melhorar a aprendizagem dos alunos".

Constatações como essas nos conduzem a reflexões acerca dos objetivos das práticas pedagógicas em SAA, dos direcionamentos metodológicos para o tratamento dos conteúdos e dos processos de formação do docente que atua nessas classes. No que se refere à leitura, acreditamos que, no âmbito da SAALP, as dificuldades do 
aluno - as quais, segundo Angelo e Menegassi (2014), referem-se basicamente à localização de informações textuais, ao estabelecimento de inferências e à interpretação - podem ser superadas por meio de situações de leitura compartilhada (SOLÉ, 1998; MENEGASSI, 2010d; BORTONI-RICARDO; MACHADO; CASTANHEIRA, 2010; BRÄNKING, 2014; BRASIL, 1998), em que o professor atua de modo a interagir com os alunos e a ensiná-los a participar ativamente da leitura, realizando antecipações, estabelecendo relações entre o texto e os conhecimentos prévios, expondo contrapalavras, construindo interpretações.

Nessa perspectiva, compreendemos que há a necessidade de envolver o professor das classes de SAALP em processos de formação contínua, entendida não como um ato de transferência ou como um conjunto de atividades isoladas e desvinculadas das urgências do contexto escolar, mas como uma ação de imersão na realidade, de reflexibilidade e de coconstrução de conhecimentos (IMBERNÓN, 2010). Para tanto, entendemos que a pesquisa-ação colaborativa consiste numa ferramenta adequada para ser utilizada na formação do docente para o trabalho com a leitura compartilhada em SAALP, visto que, em consonância com autores como Pimenta (2005), concebemos essa modalidade de pesquisa como um processo de construção de conhecimentos em que o pesquisador, como par mais experiente do processo, intervém no próprio espaço escolar, diagnosticando problemas e propondo desafios, reflexões, mudanças, de modo que o sujeito pesquisado, ou seja, o professor colaborador, conscientize-se das transformações que vão ocorrendo em si próprio e no processo e, dessa forma, desenvolva a sua autonomia docente.

Assim, buscamos, neste artigo, apresentar e discutir o trabalho docente com a leitura compartilhada em uma turma de Sala de Apoio à Aprendizagem de Língua Portuguesa (SAALP) de $6^{\circ}$ ano do Ensino Fundamental, com o intuito de refletirmos os direcionamentos possíveis ao ensino dessas tarefas, para propiciar o desenvolvimento das habilidades e das competências leitoras do aluno, a partir da noção de leitura réplica.

Inicialmente, discutimos as noções conceituais bakhtinianas de linguagem que sustentam a pesquisa, vinculando-as à concepção dialógica de leitura, bem como recuperamos os pressupostos teóricometodológicos relacionados às atividades de leitura compartilhada. Após, explicitamos a forma de coleta dos dados, assim como apresentamos e discutimos o trabalho docente com a leitura em uma SAALP, anterior e posteriormente ao desenvolvimento de ações colaborativas junto com o professor. 


\section{DIALOGISMO E LEITURA RÉPLICA}

Podemos dizer que o ponto de partida das teorizações bakhtinianas é o processo de relação entre sujeitos, processo esse sempre permeado pela linguagem. Nos termos de Bakhtin/Volochinov (1999 [1929], p. 41), a linguagem "penetra literalmente em todas as relações entre indivíduos, nas relações de colaboração, nas de base ideológica, nos encontros fortuitos da vida cotidiana, nas relações de caráter político, etc.", implicando que o sentido do texto e a significação das palavras acontecem no trabalho dialógico, interacional entre os sujeitos.

Pôr em evidência o caráter dialógico da linguagem e sob esse viés refletir a leitura e o seu ensino implica conceber o texto na perspectiva bakhtiniana de enunciado, isto é, como manifestação autêntica e objetiva da língua (BAKHTIN, 2003 [1979]). Conforme define Curado (2010, p. 143), o texto, resultado do trabalho interlocutivo, “apresentar-se-á como um 'tecido de muitas vozes', de muitos textos ou discursos, vozes que se entrecruzam, se completam, que se respondem nas relações do discurso com o processo enunciativo, com o contexto sócio-histórico, com o "outro", o que sugere um funcionamento mútuo entre autor e leitor.

Assim sendo, a leitura se apresenta como prática dialógica de confrontação com as vozes do outro, gerando réplicas (MENEGASSI, 2010a; ROJO, 2009), pois, “a cada palavra da enunciação que estamos em processo de compreender, fazemos corresponder uma série de palavras nossas, formando uma réplica" (BAKHTIN/ VOLOSHINOV, 2003[1979], p. 117-118). Ao tomarmos para reflexão o significado de "réplica", segundo as definições lexicológicas, verificamos que o verbete "replicar", nos dicionários de língua portuguesa, proporciona-nos uma visão mais ampla do que é "réplica", aproximando-se mais das discussões propostas pelo Círculo de Bakhtin. Desse modo, recuperamos o termo "replicar", conforme exposto em dois dicionários: "Replicar. V.t.d. 1. Combater com argumentos; contestar, refutar, redargüir. 2. Dizer como réplica, ou como explicação [...]" (Dicionário Aurélio Escolar da Lingua Portuguesa); "Replicar (lat replicare) vti e vint1 Responder às objeções ou críticas de; contestar, impugnar, objetar [...]" (Dicionário Michaelis Online). Esses usos, vinculados à abordagem bakhtiniana, dão a entender que "replicar" consiste em uma ação de tomar uma posição em relação ao enunciado do outro, evidenciando os elos da cadeia comunicativa, do contínuo dialógico, inerente à linguagem humana.

Menegassi (2010a), numa ampliação às definições em dicionários, ressignifica os debates do Círculo na situação de leitura 
e explica que a noção de réplica diz respeito ao leitor posicionarse como sujeito ativo e crítico diante do texto, combatendo as informações escritas com argumentos, contestando, refutando, explicando o que lê. "Réplica, neste sentido, não é vista apenas como contestação às ideias do autor do texto, mas sim como manifestação de ponto de vista sobre o que se discute no texto" (MENEGASSI, 2010a, p. 43). Assim, o sujeito que lê constrói palavras próprias, essas que surgem da apropriação e ressignificação dos discursos alheios, visto que "A nossa própria ideia [...] nasce e se forma no processo de interação e luta com os pensamentos dos outros" (BAKHTIN, 2003[1979], p. 298), ações que, segundo Menegassi (2010a), levam o leitor à produção de sentidos próprios aos textos lidos.

Na mesma linha de pensamento, Rojo (2009, p. 79, grifos da autora) conceitua a leitura como "um ato de se colocar em relação um discurso (texto) com outros discursos anteriores a ele, emaranhados nele e posteriores a ele, como possibilidades infinitas de réplica, gerando novos discursos/textos". Nesse sentido, nas práticas de linguagem do ser humano, o leitor já vem nutrido de palavras próprias para o diálogo com o texto, com as palavras alheias (GERALDI, 2010), o que amplifica as possibilidades de construção das réplicas; nessa interação, as palavras próprias alteram-se frente às opções oferecidas pelo texto, implicando a construção de novas palavras próprias pelo leitor.

A partir dessas discussões, sintetizamos, dessa forma, as características da leitura réplica: a) a leitura réplica determina que o leitor confronte-se com as palavras alheias para exprimir um ponto de vista acerca do lido; b) em virtude de o leitor já chegar ao texto repleto de palavras próprias, amplia as possibilidades de compreensão textual; c) dá origem à construção de novas palavras próprias pelo leitor; d) exige do leitor uma postura ativa, autônoma e criativa; e) prolonga a corrente da comunicação discursiva.

Ao discutir a prática de leitura escolar à luz dos conceitos dialógicos, Rojo (2009) enfatiza a necessidade de que ler na escola não seja entendido apenas como um processo de repetição de falas e textos de autor(idade) - escolar, científica - por meio de exercícios de leitura lineares e literais, os quais não permitem que as palavras próprias eclodam em sala de aula. Discorrer sobre a formação do leitor cidadão é, segundo Rojo, consentir a nossos alunos a confiança na possibilidade e as capacidades necessárias ao exercício da compreensão, o que significa ensiná-los a mesclar-se às palavras do autor, fazendo dessas palavras as próprias palavras, para adotá-las, contestá-las, criticá-las, em constante revisão e réplica (ROJO, 2009). 
Para tanto, as tarefas de leitura compartilhada, por meio das quais o professor e os alunos leem e refletem conjuntamente um texto, mostram-se como uma alternativa privilegiada para fornecer ao aluno leitor as capacidades necessárias para portar-se como respondente ativo e autônomo frente ao material trabalhado, em constante construção de palavras próprias.

\section{A LEITURA COMPARTILHADA}

Solé (1998, p. 118) define a leitura compartilhada como uma prática em que "o professor e os alunos assumem - às vezes um, às vezes os outros - a responsabilidade de organizar a tarefa de leitura e de envolver os outros na mesma". Ocorre, assim, de maneira concomitante, uma demonstração da experiência do professor e o assumir progressivo de responsabilidades de parte dos alunos em torno de estratégias basilares para uma leitura produtiva: a formulação de previsões sobre o texto a ser lido; a formulação de perguntas sobre o que foi lido; o esclarecimento de possíveis dúvidas sobre o texto; o resumo das ideias do texto. A autora explica o desenvolvimento dessas estratégias em sala de aula:

O professor e os alunos devem ler um texto, ou um trecho de um texto, em silêncio (embora também possa haver leitura em voz alta). Depois da leitura, o professor conduz os alunos através das quatro estratégias básicas. Primeiro se encarrega de fazer um resumo do que foi lido para o grupo e solicita sua concordância. Depois pode pedir explicações ou esclarecimentos sobre determinadas dúvidas do texto. Mais tarde formula uma ou algumas perguntas às crianças, cuja resposta torna a leitura necessária. Depois dessa atividade, estabelece suas previsões sobre o que ainda não foi lido, reiniciando-se deste modo o ciclo (ler, resumir, solicitar esclarecimentos, prever), desta vez a cargo de outro 'responsável' ou moderador. (SOLÉ, 1998, p. 118-119)

Essa sequência de estratégias não se mostra fixa e estática em sala de aula, pois, em determinada situação de leitura, o professor pode intervir, adicionando algum dado pertinente para uma melhor compreensão de algum trecho; em outro momento, pode sugerir que os próprios alunos apresentem ou busquem a informação necessária para um melhor entendimento do texto.

Um aspecto a ser ressaltado refere-se ao fato de que, com os apoios e os auxílios oferecidos pelo professor, a leitura compartilhada dá condições ao aluno de sentir que tem os recursos necessários para enfrentar e superar os desafios que envolvem o ato de ler. Trata-se, então, da possibilidade de desenvolver uma relação positiva com o escrito, a qual está ligada, segundo Colomer e Camps (2002, p. 65), "à própria 
experimentação do prazer que proporciona a ampliação da capacidade comunicativa e de interpretação da realidade e à autoconsciência de saber mover-se no mundo da língua impressa". Sendo assim, no compartilhamento da leitura, o professor pode tornar explícito para o aluno tudo aquilo que ele aprende a respeito da língua escrita, para que ele perceba o que já sabe e desenvolva progressivamente a autonomia no uso de uma linguagem que passa a lhe ser própria.

Na mesma perspectiva de Solé (1998), a proposta de leitura tutorial, de Bortoni-Ricardo, Machado e Castanheira (2010), toma, como pressupostos norteadores, três noções principais, derivadas tanto da teoria sociocultural da linguagem e da aprendizagem (VYGOTSKY, 1994) como da sociolinguística interacional (BORTONI-RICARDO, 2005), que consideramos importantes para a caracterização da leitura compartilhada: $1^{a}$ ) a linguagem e a interação entre as pessoas são fundamentais no processo de aprendizagem; $2^{a}$ ) as ações humanas, incluindo-se também a linguagem, constituem processos estabelecidos de forma cooperativa e conjunta pelos interagentes; $3^{\text {a }}$ ) o conceito de andaimagem, ancorado nas duas primeiras noções e se referindo "a um auxílio visível ou audível que um membro mais experiente de uma cultura pode dar a um aprendiz". (BORTONI-RICARDO; MACHADO; CASTANHEIRA, 2010, p. 26). Sob esse ponto de vista metodológico, o professor guia o aluno na leitura dos diversos textos, "atuando como seu tutor (daí o termo leitura tutorial), visto que a leitura deve ser compartilhada, envolvendo tanto aquele que direciona (o professor mediador) como o aluno (também agente em todo o processo)" (BORTONI-RICARDO; MACHADO; CASTANHEIRA, 2010, p. 60). Uma característica reafirmada nessa proposta, destacada pelas autoras, é a possibilidade de o aluno assumir uma postura ativa diante do texto: "os próprios alunos devem selecionar as marcas do texto, formular hipóteses e verificá-las, enfim, construir sua interpretação. Os alunos devem ser os responsáveis pelo desenvolvimento de sua compreensão leitora [...]" (BORTONIRICARDO; MACHADO; CASTANHEIRA, 2010, p. 57).

Por esses aspectos, a leitura compartilhada não se confunde com leitura dirigida, pois nesta o professor conduz a leitura e expõe sua compreensão sobre o texto, tornando os alunos "participantes passivos", que apenas respondem às perguntas (SOLÉ, 1998, p. 121), sem demonstração de posicionamento e diálogo com o professor e com o texto. Já na leitura compartilhada o professor devolve para o aluno a responsabilidade e o controle da atividade leitora, exigindolhe uma participação muito mais vivaz. 
Nos Parâmetros Curriculares Nacionais, a leitura compartilhada é chamada de leitura colaborativa, sendo definida como "uma atividade em que o professor lê um texto com a classe e, durante a leitura, questiona os alunos sobre as pistas linguísticas que possibilitam a atribuição de determinados sentidos" (BRASIL, 1998, p. 61). Embora se destaque a importância do envolvimento do aluno no processo, o qual explicitará para os colegas os procedimentos que utiliza para atribuir sentido ao texto, a definição oferecida pelo documento não evidencia as contribuições partilhadas entre o professor, o texto e o aluno, sugerindo dois papéis bem demarcados: do professor, o de questionar os alunos; do aluno, portanto, o de responder ao que o professor pergunta.

De forma mais elucidativa, Bräkling (2014) aponta a leitura colaborativa, ou compartilhada, como aquela em que alunos e professor leem em conjunto um mesmo texto, paulatinamente, expondo suas ideias e impressões acerca do que foi lido. Em diálogo com as discussões de Rojo (2009) acerca da leitura réplica, Bräkling (2014) ressalta que a leitura compartilhada tem finalidade de propiciar condições para que os procedimentos - as ações concretas envolvidas na leitura, como, por exemplo, sublinhar uma informação relevante numa leitura de estudo - e as capacidades de leitura - concernentes ao processo de decodificação, de compreensão e de apreciação e réplica em relação ao texto lido - sejam explicitados pelos diferentes leitores, de modo que uns se apropriem das estratégias empregadas por outros, desenvolvendo e aprofundando sua competência leitora.

A leitura em conjunto com o aluno envolve atividades que são feitas antes de iniciar a leitura propriamente, durante e depois de terminada, tendo em vista a especificidade das capacidades que são tematizadas (BRÄKLING, 2014). Assim, a leitura simultânea, sendo esta o momento em que o professor e os alunos leem pequenos trechos do texto e questionam acerca dos significados e sentidos construídos, consiste em uma das fases da leitura compartilhada.

Bräkling (2014) destaca, ainda, que a leitura colaborativa fundamenta-se no pressuposto teórico-metodológico de que se aprende em colaboração com o outro; desse modo, "o texto a ser lido precisa ser aquele para o qual os alunos não possuam proficiência autônoma, pois, se assim fosse, não precisariam de colaboração para recuperar os sentidos do texto". Por esse motivo, fica confirmada a importância dessa prática de leitura junto a alunos que apresentam dificuldades de aprendizagem, como é o caso dos alunos de SAALP.

\section{O TRABALHO DOCENTE COM A LEITURA COMPARTILHADA}




\section{Situação inicial de leitura em SAALP}

A investigação definiu-se como pesquisa-ação colaborativa, a qual, conforme Pimenta (2005), apresenta como característica principal a possibilidade de o professor analisar, refletir e alterar suas práticas, fortalecendo-se como pessoa e como profissional.

Com o intuito de levantarmos dados para o trabalho colaborativo, participamos de duas horas-aula em que o professor trabalhou a leitura sem qualquer intervenção teórico-metodológica ${ }^{1}$. Sintetizamos o que constatamos quanto às direções dadas aos alunos nessas aulas:

- as perguntas orais realizadas pelo professor, tanto na fase de pré-leitura como na de pós-leitura, mostram-se demasiadamente genéricas, triviais, pouco desafiadoras, sem vinculação com as ideias do texto, não se promovendo, assim, a motivação e o levantamento de hipóteses que dão uma finalidade para a leitura (SOLÉ, 1998). Além disso, exigem uma única resposta, que deve ser breve, dirigindose, portanto, à busca da homogeneidade;

- o primeiro contato dos alunos com o texto é por meio da leitura em voz alta, sendo que cada aluno deve ler um fragmento para a classe. No decorrer dessa leitura, o professor auxilia na pronúncia correta de algumas palavras e pede atenção à pontuação, mas, muitas vezes, não deixa 0 aluno concluir o período para solicitar a continuidade pelo próximo aluno, escolhido de surpresa. Tais procedimentos evidenciam para o aluno a necessidade de se atentar ao "como dizer" em detrimento dos sentidos textuais;

- após a leitura em voz alta e uma breve conversação a respeito do texto, os alunos devem responder por escrito às perguntas de leitura, entretanto as perguntas consistem em repetições das que foram apresentadas antes da leitura e após a leitura, não se propiciando ao aluno a oportunidade de ampliar gradativamente os conhecimentos;

- no procedimento de elaboração de perguntas de leitura, o processo de leitura é desconsiderado (MENEGASSI, 2010b), pois a maioria das perguntas configura-se como perguntas de elaboração pessoal (SOLÉ, 1998), sem promover o estudo das informações textuais;

- enquanto os alunos respondem às perguntas, não há intervenções por parte do professor no sentido de auxiliá-los a compreender os comandos e o texto lido. Também, após 
os alunos realizarem a tarefa, não se desenvolve qualquer conversação a respeito das respostas dadas pelos alunos;

- na maioria das vezes, os alunos revelam uma postura acrítica, não questionadora, ao apresentarem respostas breves ou incompletas, as quais apenas informam que eles executaram a tarefa proposta, como uma atividade rotineira da sala de aula. Por não ocorrer discussão após a resolução dos exercícios, essas respostas encerram, assim, a continuidade da corrente dialógica.

De maneira geral, é possível constatar que a aula de leitura "toma o princípio da repetição como sua essência, em benefício da estabilização (de formas e sentidos), funcionando como uma política de contenção: repita, não busque o novo" (GERALDI, 2010, p. 144). Obscurece-se, assim, o papel preponderante que a prática leitora exerce no desenvolvimento e no aprofundamento da reflexão acerca dos fatos que circundam o sujeito.

\section{Ações colaborativas junto com o professor de SAALP}

Após constatarmos nas atividades de leitura algumas lacunas no processo de ensino na SAALP, como, por exemplo, a ausência de reflexão e de diálogo a respeito dos textos lidos, foi iniciado o trabalho colaborativo junto com o professor.

A abordagem dos textos teóricos e metodológicos sobre as concepções e o processo de leitura enfatizou os pressupostos da leitura compartilhada. Por um período de três meses, os textos foram trabalhados com o professor, com o intuito de: a) estudar as concepções e as etapas do processo de leitura; b) discutir as estratégias de leitura e seu ensino na escola; c) pontuar as atividades que podem ser realizadas com o aluno antes da leitura, durante a leitura e após a leitura; d) refletir acerca da prática de leitura compartilhada em SAALP.

Para orientar a abordagem desses textos, o professor recebeu roteiros de discussão, com planos de estudo de conceitos relacionados à leitura, como também de atividades que instigavam a reflexão sobre a prática em SAALP e a elaboração de propostas, específicas para esse contexto, que focalizavam o ensino da leitura. $\mathrm{O}$ material era entregue ao professor uma semana antes das sessões reflexivas para a discussão acerca do trabalho com a leitura em SAALP. Solicitamos que o professor lesse os textos, refletisse e respondesse às questões propostas no roteiro, para que, posteriormente, debatêssemos nas sessões reflexivas. 
Foram realizadas seis sessões reflexivas, todas gravadas em vídeo. As sessões ocorreram na biblioteca da escola, na hora-atividade do professor; cada uma teve a duração de 50 minutos.

Um dos tópicos de discussão nas sessões reflexivas consistiu nas especificidades da leitura em voz alta e da leitura silenciosa, conforme pontua o Episódio ${ }^{2} 1$. Essa discussão deu-se em virtude de percebermos, em uma das aulas observadas em SAALP, já durante o trabalho colaborativo com o professor, a primazia pela leitura em voz alta em detrimento da leitura silenciosa.

Episódio 1: Pesq. - [...] Outra coisa que eu notei é que você pede a leitura em voz alta do texto ou faz, você a leitura em voz. alta... É importante que sempre a primeira leitura do texto seja a leitura silenciosa... é bastante comum se fazer a leitura em voz. alta antes da silenciosa... Normalmente o professor pede para um aluno ler o texto ou uma parte do texto... o que acontece é que esse aluno vai o texto se preocupando muito mais com a forma do que com o conteúdo... muitas vezes o aluno fica até muito nervoso... depois de ler ele não sabe nem de que assunto o texto tratou... porque quando ele leu ele estava preocupado com a forma...

Prof. - Eu nunca parei pra pensar nisso... Eu fico me questionando se na hora que o aluno está lendo é conveniente fazer as correçoes!? Isso não vai atrapalhar a leitura?

Pesq. - Você fazendo isso... cria mais obstáculos para a compreensão... porque interrompe o processo... o fio da leitura... outra coisa é que você diminui a velocidade da leitura... Quanto mais devagar ... mais devagar é a compreensão...

Prof. - Então eu fico pensando que se eu interrompo ele na leitura e mais as dificuldades que ele já tem... então corto e dá uma quebra...chega no final do parágrafo você faz. umas três quebras mais as dificuldades que ele tem...

Nesse diálogo, buscamos destacar junto com o professor que a leitura em voz alta possui características bastante diferentes da leitura silenciosa. Segundo Vygotsky (2000, p. 198, tradução nossa),

a vocalização dos símbolos visuais dificulta a leitura, as reações verbais atrasam a percepção, travam-na, fracionam a atenção. Por estranho que possa parecer, não somente o próprio processo da leitura, mas também a compreensão é superior quando se lê silenciosamente.

Nesse sentido, o entendimento do conteúdo do texto é maior com a leitura silenciosa do que com a leitura em voz alta. Isso porque a vocalização dos signos dificulta a atenção às informações textuais e promove uma leitura mais lenta, portanto com menos velocidade de compreensão. Já a leitura silenciosa é mais rápida: o próprio processo de movimento dos olhos e a percepção das letras tornam-se mais velozes, como também os movimentos de retorno dos olhos são menos frequentes (VIGOTSKI, 2000), o que permite ao leitor aterse ao conteúdo e produzir inferências. 
Assim, a orientação ao professor para que o aluno sempre leia silenciosamente o texto antes de lê-lo em vozalta e de forma compartilhada mostrou-se bastante profícua, provocando reflexões no professor acerca de suas ações em SAALP no desenvolvimento da leitura em voz alta e levando-o a concluir: "Então eu fico pensando que se eu interrompo ele na leitura e mais as dificuldades que ele já tem... então corto e dá uma quebra".

Posteriormente às sessões reflexivas e ao desenvolvimento de algumas tarefas de leitura compartilhada ou tutorial em SAALP, houve um momento de discussão com o professor sobre as atividades e os procedimentos desenvolvidos com os alunos, em sala de aula:

Episódio 2: Pesq. - Uma coisa que eu notei.. e que farparte até da nossa ansiedade como professor... é que você termina de ler o parágrafo e já explica pro aluno o que foi lido... não sei se você já notou isso?!

Pesq. - Não... mas então qual seria o correto?

Pesq. - O ideal é deixar um tempo para o aluno pensar... que ELE faça um resumo sobre o que foi lido... formule uma explicação... geralmente você lê o parágrafo ou a frase e explica... 'então aqui diz isso... isso... isso...'

Prof. - Ah... tá... então deixar que eles tirem uma conclusão?

Pesq. - Isso... então, você pode perguntar... 'o que vocês entenderam dessa parte que nós lemos?... o que informa esse parágrafo ou nessa parte?'

Prof. - Então... na leitura feita por parágrafos... deixar que os alunos tirem a conclusão deles [anotando por escrito, no roteiro de discussão]

Pesq. - Para que então você como professor faça as intervenções necessárias... verifique se o que ele explica é condizente com que o que foi lido...

No episódio, tecemos uma crítica a respeito da forma como o professor conduz a discussão de texto em sala de aula: "vocêtermina de ler o parágrafo e já explica pro aluno o que foi lido...". Como o professor diz não ter percebido isso e demonstra preocupação com esse apontamento - "mas então qual seria o correto?", fornecemos algumas orientações: "o ideal é deixar um tempo para o aluno pensar... que ELE faça um resumo sobre o que foi lido... formule uma explicação"; "...então, você pode perguntar... 'o que vocês entenderam dessa parte que nós lemos?.. o que informa esse parágrafo ou nessa parte?"; "que então você como professor faça as intervenções necessárias". Assim, nesse diálogo, buscamos pôr em discussão a primazia da voz do professor na situação de leitura, que tolhe a construção de réplicas e a ampliação dos sentidos textuais e estimula a formação de leitores que apenas apreendem e repetem leituras do professor (GERALDI, 2010), e incentivamos uma prática atrelada à concepção dialógica de linguagem e de leitura, em que o aluno aparece como sujeito leitor coprodutor, que reflete, interage e trabalha com o texto e constrói suas compreensões, características favorecedoras de um processo de participação crítica nas circunstâncias vividas pelo leitor. 


\section{Situação em SAALP após as ações colaborativas}

Trazemos para análise e discussão duas aulas em que o professor trabalhou a leitura do texto "O tesouro escondido", de D'Olim Marote (s/d). Cada aula teve duração de 50 minutos e contou com a participação de nove alunos, após o trabalho efetuado com a leitura e a discussão dos textos teórico-metodológicos.

\section{O tesouro escondido}

Luis, Paulo e Renato estavam brincando no porão da casa do seu avô. Luis remexia livros e papéis. Paulo e Renato brincavam de pirata. De repente, Luis exclamou:

_ Paulo! Renato! Vejam só o que eu achei! _ E balançava na mão um papel encardido e grosso.

_ Que papel é esse? _ Indagaram os dois, com curiosidade estampada em seus olhinhos vivos.

_ Vocês não vão acreditar! Encontrei um mapa com pista de um tesouro de verdade!

Mal acreditando no que viam, os três estenderam o velho papel no chão e passaram a estudá-lo.

_ Vejam, o lugar que está apontando no mapa é perto daqui! _ Exclamou Luis.

_ Precisamos contar tudo para o vovô. _ Disse Paulo.

_ Ora não seja bobo! _ Retrucou Renato. _ Ninguém precisa saber de nada. Vamos logo!

Rapidamente, os três saíram do porão, muniram-se de pás e enxadas e puseram-se a caminho do tesouro. Cada um ia pensando no que fazer com tanta riqueza.

_ Quero comprar bastante doces! _ Imaginava Luis.

_ Hei de ter um montão de brinquedos! _Contava Renato.

_ Vou repartir minha fortuna com os pobres!_ Sonhava Paulo.

Paulo, Renato e Luis já se encontravam no lugar onde o tesouro tinha sido enterrado. Os garotos cavaram longo tempo, sem parar. Já estavam cansados e a ponto de desistir, quando a pá tocou em alguma coisa metálica. Era o momento esperado! Com o coração aos pulos 21, os três tiraram a terra o mais rapidamente possível. Por fim, depararam com um baú velho e comido pela ferrugem. Fizeram várias tentativas para abrilo, mas não conseguiram, o fecho estava emperrado. Finalmente depois de muito esforço, o baú foi aberto. Mas que decepção! Nenhum tesouro apareceu a seus olhos. No fundo do baú havia apenas um bilhete do avô fazendo uma brincadeira. Eles concordaram sorrindo.

D’Olim Marote 
Como procedimento inicial, o professor solicitou que todos fizessem a leitura silenciosa, momento em que os alunos tiveram o primeiro contato com o conto e puderam constituir significados individuais para a leitura. A abordagem das especificidades da leitura silenciosa e da leitura em voz alta, nas ações colaborativas, demonstrou resultados satisfatórios, pois o professor aprendeu que nem todos os textos cabem a uma leitura em voz alta com muita eficácia; compreendeu também que, para um texto como "O tesouro escondido", a leitura silenciosa permite ao leitor seguir seu próprio ritmo e ir formando uma imagem dos fatos e das descrições apresentados pelo narrador, propiciando-lhe a produção de sentido do texto (MENEGASSI, 2010e).

O professor aguardou alguns minutos, até que todos lessem o conto, e disse aos alunos: "Então, o professor vai ler e gostaria que vocês fossem acompanhando a leitura e, se possivel, participando, no momento certo", evidenciando a intenção de desenvolver a leitura compartilhada, em que o aluno não é mero ouvinte, mas participante ativo da leitura. Depois de ler o título "O tesouro escondido", procurou destacar a importância desse elemento para a compreensão do texto:

Cena 1: Prof. - 'O tesouro escondido'... Sempre que você vai iniciar a leitura... lembre-se daquelas situações... se tiver ilustrações... elas me ajudam a entender... no caso aqui eu só tenho o texto... mas ai eu vou pelo título... o tesouro escondido/ / Na minha imaginação... já começa a surgir algumas ideias... do que vai tratar o texto... já começo a lembrar de algumas coisas talvez que eu já li... de um filme que eu já assisti... que tem a ver com tesouro / / Não foi isso que aconteceu com vocês antes de fazer a leitura? Então... o título já é a primeira informação... já começa a atiçar a tua curiosidade... O que que é um tesouro? L23 - Ouro...

Prof. - Ouro? Então... na tua cabeça é alguma coisa cheia de ouro...

F8 - De um baú...

Prof. - De um baú? Dá onde que veio essa tua imagem? De alguma coisa que você já assistiu? De algum filme?

F8 - Filme de pirata.

Prof. - Filme de pirata? E você V20, também lembra de um baú cheio de ouro? V20 - É...

Nesse diálogo, o professor, recuperando as discussões nas ações colaborativas, procura demonstrar que a atividade leitora envolve ativamente o leitor desde as primeiras palavras do texto, ao destacar que o título do texto mobiliza conhecimentos de natureza muito variada - "[...] já começo a lembrar de algumas coisas talvez que eu já li... de um filme que eu já assisti..." - como também desperta o interesse do leitor "[...] já começa a atiçar a tua curiosidade... O que que é um tesouro?”. Assim, 
o professor torna explícita a dialogicidade na linguagem, recuperando outros dizeres que estão em relação com o texto e envolvendo o aluno como sujeito que toma parte da construção do texto, características constitutivas das práticas de leitura compartilhada.

Ponderamos, no entanto, que essa conversação poderia ser realizada antes da leitura silenciosa, do primeiro contato dos alunos com o material escrito, de forma a trabalhar a motivação e a autoconfiança do leitor, a estabelecer uma finalidade para a leitura e ensinar o aluno a realizar previsões sobre o texto (SOLÉ, 1998; BORTONI-RICARDO; MACHADO; CASTANHEIRA, 2010; MENEGASSI, 2010d), enriquecendo a constituição dos significados individuais para a leitura.

O professor continuou lendo o texto, até o final do segundo parágrafo, quando realizou novos questionamentos e comentários:

Cena 2: Prof. - E aí?... 'balançava na mão um papel encardido e grosso'... Do que que eles estavam brincando mesmo?

L23 - De pirata.

Prof. - De pirata! Aí já me vem uma ideia... né? Tesouro... aí já vi a palavra pirata... isso já vai agucando minhas ideias do que se trata... aí já vem a imagem do baú cheio de ouro... então são imagens que a gente tem... quando se fala em tesouro geralmente a gente lembra disso... e ai a gente fica imaginando... o que seria esse papel encardido... Encardido... significa o quê? Que o papel já era...

L26 - Sujo...

Prof. - Sujo... o que mais?

F8 - Antigo...

L23 - Usado..

Prof. - Antigo... usado... então, se o papel estava encardido, supostamente fazia tempo que tava ali... [...] Vejam que eles estavam brincando no porão da casa... onde tem coisas velhas... antigas... então a palavra encardido dá ideia de coisa velha... antiga...

Nessa situação, notamos que o professor recupera as discussões anteriores, sintetizando o que foi lido até o momento, relembrando os conhecimentos acionados inicialmente, confirmando as antecipações realizadas, por meio da estratégia de verificação (BRASIL, 1998), estabelecendo relações entre as informações do texto, ativando outros conhecimentos do leitor. Assim, por meio dessas intervenções, o texto, na leitura compartilhada, constitui-se para o aluno como um todo significativo. Nesse sentido, um aspecto que se destaca na Cena 2 é o trabalho com a definição da palavra "encardido", visto que o professor não se contenta apenas que os alunos mencionem os sinônimos possíveis da palavra - "sujo", "antigo", "usado"-, mas busca relacionar a palavra na conjuntura do texto - "Vejam que eles estavam brincando no porão da casa" -, favorecendo 
a formação de um leitor que analisa, reflete, relaciona, conclui.

$\mathrm{O}$ professor deu prosseguimento à leitura e fez novas interrupções e comentários ao longo da história. Em um dos momentos, procurou discutir com os alunos o significado da palavra "estampada":

Cena 3: Prof. - O que seria 'curiosidade estampada'? Estampada significa o quê?

Alunos - (silêncio)

Prof. - Como fazemos para descobrir o que é estampada?

L23 - Pegar dicionário...

Prof. - Pode ser... mas se toda vez, que a gente pegar um dicionário quando encontrar uma palavra que não conbece... ou se toda vez, você fica perguntando para o professor 0 significado das palavras... o que que acontece? A leitura não anda... nós podemos fazer o quê... descobrir pelo próprio texto... vamos pensar juntos... quando encontraram o papel... a curiosidade estava estampada em seus olhinhos vivos... arregalados... então a curiosidade... C3 - Era vista...

Prof. - Isso... estava bem marcada... bem percebida... não é... qualquer um podia notar... Então sempre que encontrar uma palavra que você não sabe... procure antes ler de novo e tente descobrir pelo próprio texto... o próprio texto dá essas informações para você...

Nessa ocasião, o professor questiona o procedimento adotado por muitos leitores de recorrer ao dicionário ou ao professor nas circunstâncias em que se deparam com dificuldades em desvendar o significado de palavras desconhecidas no texto, explicando aos alunos que, com essas estratégias, "a leitura não anda", atravancando a atividade compreensiva. Além disso, o professor propõe-lhes deduzir o que uma palavra significa a partir do contexto: "descobrir pelo próprio texto", pois "o próprio texto dá essas informaçõespara você", assinalando-se outra característica da leitura compartilhada: de ensinar o aluno a resolver os problemas de compreensão. Ainda, o convite explícito "vamos pensar juntos..." traz à tona a intenção de delegar gradativamente responsabilidades ao aluno, tornando-o um partícipe da construção da leitura.

Em concordância com as orientações dadas pelo professor, entendemos que os alunos de SAALP podem e precisam ser instigados a se valer das informações contidas num dicionário. Entretanto, esse artifício consiste em um último recurso, quando as demais estratégias de construção de sentido não surtirem resultados. Conforme destaca Leffa (2001), a consulta ao dicionário é extremamente obstrutiva, pois obriga o aluno a várias ações - interromper a leitura; buscar a palavra no dicionário, percorrendo várias páginas; retornar ao texto. Em se tratando de alunos com dificuldades de compreensão leitora, essa sequência de ações gera ainda mais embaraços para o processo de compreensão, visto que o aluno interrompe o fluxo de concentração, distancia-se da leitura, do envolvimento com o texto 
e das possibilidades de construção de sentidos. Assim, é preferível que os alunos de SAALP sejam ensinados a chegar ao significado das palavras de um texto a partir das pistas que ele traz.

$\mathrm{Na}$ sequência, o professor leu mais fragmentos do texto para, então, realizar novos questionamentos e comentários:

Cena 4: Prof. - 'Vocês não vão acreditar! Encontrei um mapa com pista de um tesouro de verdade! Mal acreditando no que viam, os três estenderam o velho papel no chão e passaram a estudá-lo'... Então aí eu retomei aquela ideia de tesouro... Então... vão imaginando a cena... acharam o papel... colocaram no chão para estudar... estudar o quê??

L23 - Onde estava o tesouro...

$\mathrm{V} 20$ - O mapa...

Prof. - O mapa... Olhem... Estenderam o velho papel no chão e passaram a estudá-lo... Estudar o velho papel... o mapa...Para estudar onde estava o tesouro... então se eu tenho um mapa eu tenho que estudar... como que se fazpara estudar um mapa?

(silêncio)

Prof. - Como vocês fazem em geografia... por exemplo...pra estudar o mapa... o que a gente precisa saber principalmente?... o básico principalmente...eu preciso saber pelo menos onde fica o norte...

Alunos - Sul... leste...oeste...

F8 - Saber onde o sol nasce...

$[\ldots]$

Prof. - O minimo que a gente precisa saber... Então esse conbecimento os meninos supostamente teriam que ter...

$[\ldots]$

Prof. - Vejam que tudo isso que nós estamos falando... não está no texto... não está escrito que os meninos tinham algum conhecimento de geografia... que sabiam os pontos ...lá... norte... sul... leste... oeste... tudo isso aparece resumido na palavra estudar... vejam então como é importante sempre procurar saber mais... é como uma corrente... sabendo mais... en leio melhor e lendo eu fico sabendo mais...

As interferências iniciais trazem uma síntese do lido até o momento - "... acharam o papel... colocaram no chão para estudar" -, evidenciando a estratégia de seleção (BRASIL, 1998), isto é, a escolha de informações úteis para a compreensão, para se chegar, então, ao trabalho com a inferência textual e extratextual. A primeira aparece quando o professor questiona a respeito do antecedente do pronome pessoal - "colocaram no chão para estudar... estudar o quê??" -, referindo-se, portanto, ao estabelecimento de ligações entre partes do texto com a finalidade de manter a sua coerência. A segunda surge no momento em que os alunos são questionados: "como que se faz.para estudar um mapa?", implicando, assim, o relacionamento entre as informações do texto e o conhecimento de mundo do leitor. Para finalizar a exposição, o professor explica que as inferências não estão explícitas no texto; há uma série 
de conhecimentos que o leitor precisa levar para a situação de leitura, aprofundando a atividade leitora. Tais discussões refletiram o trabalho nas ações colaborativas, em que se abordou a noção de inferências e provocou no professor a percepção da dialogicidade na linguagem e na leitura - "é como uma corrente... sabendo mais... eu leio melhor e lendo eu fico sabendo mais..." -, ilustrando como os elos na cadeia da comunicação são contínuos, ininterruptos (BAKHTIN/VOLOCHINOV, 1999[1929]).

Segundo Menegassi (2010c, p. 78), "as estratégias de leitura com o emprego de inferências de ligação textual e inferências extratextuais necessariamente precisam ser ensinadas e praticadas com os alunos, para o bom desenvolvimento do leitor, durante seu processo de formação" e as tarefas de leitura compartilhada, nas quais ocorre o trabalho de interação entre o leitor em formação - o aluno do Ensino Fundamental - o professor e o texto - e seu autor -, mostram ser uma alternativa pertinente para se ensinar a construção de inferências, permitindo o desenvolvimento do leitor competente.

Logo após o professor concluir a leitura simultânea, ocorre a manifestação de um dos alunos da SAALP:

Cena 5: V20 - Diz que tem no mato assim um círculo de pedra e direm que tem panela de dinheiro enterrada... e quando passa perto tem uma luzona lá...

Prof. - Ah... éb!!!!

V20 - E quem tira o dinheiro da panela logo morre... porque tinha um lá que achou uma panela e logo depois morreu...

(risos)

Prof. - Essa história de panela de ouro... principalmente quem tem parentes no interior sempre escuta... né... isso até algum tempo atrás...tinha uma explicação... as pessoas... nos tempos de guerra... viviam fugindo... e não tinha como carregar as coisas que tinham ... aí o dinheiro... as coisas de valor... as pessoas enterravam pra ninguém encontrar... com a ideia era de voltar pro lugar e ai ter alguma coisa que era deles...

F8 - Minha vó sempre contava que existia panela de dinheiro... lá na chácara dela... tinha uns que tiraram panela de dinheiro e ficaram ricos...

L26 - Um dia meu tio foi tirar uma panela de ouro e tinha água benzida... um santinho... e diz. que quando tavam tirando apareceu um cachorro... eles pensaram que era assombração (risos)... E dai saíram correndo e deixaram santinho e tudo...

(risos)

Prof. - (risos) Eles acharam que era assombração e era um cachorro!!!???

V20 - Mas dir que também... só encontra de noite... de dia não...

Prof. - Ah... então tem ser corajoso!!!!

L23 - Vou perguntar pro meu pai se é verdade...

Prof. - Vocês ainda têm oportunidade de escutar isso do avô de vocês... mas essas histórias ai estão se perdendo... 
Verificamos que, nessa cena, o aluno V20 toma a iniciativa de trazer para a leitura uma história contada em seu meio social, acionando outras histórias por parte do aluno L26 e do aluno F8, o que despertou o interesse de L23 em verificar com seu pai a veracidade dessas histórias. O professor atua demonstrando interesse no que foi contado por V20 - Ah...éb!!!?? -, bem como tecendo explicações acerca do que foi explicitado pelo aluno, prolongando a cadeia comunicativa.

Após a leitura do texto, o professor entregou aos alunos nove comandos de atividades.

1) $O$ que os meninos estavam fazendo quando encontraram o papel encardido?

2) O que era o papel encardido que os meninos encontraram?

3) O que eles decidiram fazer após terem encontrado o mapa?

4) O que eles imaginaram fazer com o tesouro?

5) Qual dos personagens estaria utilizando o tesouro de forma mais correta?

6) Se você encontrasse o tesouro, o que você faria com ele?

7) O que aconteceu no lugar indicado pelo mapa?

8) Você concorda com a brincadeira feita pelo avô dos meninos?

9) Com base nas respostas anteriores, escreva o que você entendeu do texto.

Nota-se que os comandos propiciam um trabalho efetivo com o texto, refletindo a abordagem das etapas do processo de leitura (MENEGASSI, 2010a; 2010b), no decorrer das ações colaborativas. Assim, por meio das perguntas 1), 2) e 4), requisita-se a localização de informações textuais, quando o leitor recupera e produz significados no processamento da decodificação - primeira etapa do processo da leitura; através das perguntas 3) e 7), torna-se possível a produção de inferências - segunda etapa do processo, em que o leitor adentra o texto para estabelecer relações entre as informações do texto e para articular os dados textuais com as suas experiências individuais; por meio das perguntas 5), 6) e 8), solicita-se a interpretação textual - terceira etapa do processo, na qual o leitor usa sua capacidade crítica para analisar, refletir, julgar, expandir as informações, gerando um novo dizer, já que este já possui uma natureza criativa e autônoma. Nesse processo, o aluno pode ir além das linhas, para examinar o que foi lido, debater posicionamentos a partir da interação com o autor, via texto, estabelecendo a noção de leitura réplica (ROJO, 2009; MENEGASSI, 2010a).

Assim, as perguntas oferecidas aos alunos da SAALP 
mostram-se eficientes para o desenvolvimento do leitor, pois levam em consideração as etapas do processo de leitura que exigem do aluno o trabalho de construção do significado do texto, partindo de níveis mais elementares da leitura, passando pela etapa da compreensão inferencial, a qual possibilita ao leitor realizar incursões no texto, construindo informações a partir das pistas deixadas pelo autor (MENEGASSI, 2010b), até chegar aos níveis mais complexos, da interpretação e da produção de palavras próprias.

Ao dar sequência às atividades de leitura, o professor buscou prestar auxílios aos alunos enquanto eles produziam as respostas, suscitando diversos momentos de interação, dando continuidade à leitura compartilhada. Destacou a necessidade de escrever respostas completas, porque "as respostas completas mostram o que vocês de fato compreenderam do texto". Essa orientação do professor consiste em um resultado das ações colaborativas em que a produção da resposta foi abordada como uma prática de linguagem em que o autor/aluno, orientado pelo professor em sala de aula, busca responder a uma pergunta, explicitando a compreensão a respeito de um texto e/ou defendendo seu ponto de vista sobre o que lhe foi perguntado.

$\mathrm{Na}$ discussão relativa à pergunta, percebe-se que o aluno L23 procura atender as orientações do professor:

Cena 6: Prof. - O que aconteceu no lugar indicado pelo mapa?

L23 - Eles encontraram um ouro... no lugar indicado pelo mapa eles encontraram ouro..

Prof. - Ouro? Será? ... mas tinha ouro?

F8 - Não ... tinha um baú... e dentro...

L23 - E dai tentaram abrir... e não conseguiram abrir... e dai acharam um papel... que era uma carta lá do vô deles...

Inicialmente, o aluno L23 estrutura a resposta de forma abreviada - "Eles encontraram um ouro"-, a qual apresenta apenas os dados solicitados, sem recuperação da temática expressa na pergunta, mas logo reformula o texto, trazendo parte da pergunta, com a temática - "no lugar indicado pelo mapa” -, e, em seguida, acrescentando a informação requisitada, com base nas discussões ocorridas em sala de aula - "eles encontraram ouro". A informação apresentada pelo aluno é questionada pelo professor, o que levou o aluno F8 a auxiliar o colega, o qual expande a discussão, com uma síntese do texto, dando evidências da compreensão deste. Nesse sentido, a discussão acerca das perguntas e das respostas de leitura mostra-se como uma das fases da leitura compartilhada.

Em alguns momentos da atividade, os alunos mostram-se em processo de constituição da autonomia leitora, discutindo com os pares as respostas dadas. Exemplo disso foi quando o aluno 
F8 demonstrou sua dúvida ao aluno L23, o que desencadeou uma discussão entre L23, F8 e L26:

Cena 7: L23 - 'Qual dos personagens estaria utilizando o tesouro de forma mais correta?'... foi o Paulo... porque ele vai repartir com os pobres...

L26 - Êê... mas ninguém faz isso... já viu alguém ganhar na loteria e dividi com os pobres...

L23 - Mas é ele que está fazendo certo... Jesus dividia com os pobres...

F8 - Ah... se eu achasse uma panela de dinheiro eu ía ajudar a minha mãe... meus amigos...

Nesse debate, os alunos acionam novamente outros dizeres, vindos de outros modos de atuação na sociedade - ganhar na loteria; Jesus dividia com os pobres; se eu achasse uma panela de dinheiro, o que faz da sala de aula um espaço de vozes conflitantes, em debate. Esse confronto foi possível porque a intervenção anterior do professor foi bastante significativa, permitindo que as histórias aflorassem em sala de aula e incentivando a aprendizagem cooperativa.

Após o trabalho com as respostas textuais, inferenciais e interpretativas, o professor abordou a última questão: "Com base nas respostas anteriores, escreva o que você entendeu do texto". Explicou aos alunos: "Vocês vão fazer o que fizemos nas aulas anteriores... pegar as respostas dadas, juntar tudo e escrever um novo texto...", orientando-se pela metodologia defendida por Menegassi (2010b, 2011), que encaminha o trabalho com a "resposta-final" (RODRIGUES, 2013, p. 165), na qual se agrupam em um só texto todas as informações apresentadas nas respostas anteriores. Embora a questão formulada não deixe explícita a intenção do professor, a metodologia mostra-se bastante adequada para as tarefas de leitura compartilhada no contexto da SAALP, uma vez que rompe com a abordagem fragmentada de leitura em sala de aula, em que o aluno é impelido a responder várias perguntas, sem, muitas vezes, perceber a relação entre elas e sem conseguir reconstituir a partir delas "a organização do pensamento realizado durante a leitura" (RODRIGUES, 2013, p. 63).

Retomamos, para análise, as respostas às perguntas de leitura atribuídas por L23 e a resposta-final:

1) O que os meninos estavam fazendo quando encontraram o papel encardido?

Os meninos estavam brincando de pirata quando encontraram um papel encardido e grosso.

2) O que era o papel encardido que os meninos encontraram?

O papel encardido que os meninos encontraram era um mapa.

3) O que eles decidiram fazer após terem encontrado o mapa?

Os meninos decidiram ir atrás do tesouro com a ajuda do mapa. 
4) O que eles imaginaram fazer com o tesouro?

Com o tesouro Luís imaginava comprar bastante doces. Renato pensava em comprar um montão de brinquedos. Paulo queria repartir o dinheiro com os pobres.

5) Qual dos personagens estaria utilizando o tesouro de forma mais correta?

O personagem que estaria utilizando o tesouro de forma mais correta foi o Paulo.

6) Se você encontrasse o tesouro, o que você faria com ele?

Eu iria ajudar os pobres, dar cestas básicas para quem precisa, dar roupas e também ajudar no asilo, nos hospitais, orfanatos e etc.

7) O que aconteceu no lugar indicado pelo mapa?

No lugar indicado pelo mapa foi encontrado um baú com um bilhete do avô fazendo uma brincadeira com eles.

8) Você concorda com a brincadeira feita pelo avô dos meninos? Eu não concordo com a brincadeira feita pelo avô dos meninos. Eles sofreram muito para achar o baú e bem no fim era apenas um bilhete com uma brincadeira mal feita.

9) Com base nas respostas anteriores, escreva o que você entendeu do texto.

Luís, Renato e Paulo estavam brincando no porão da casa do avô quando encontraram um papel encardido e grosso. Esse papel era um mapa de um tesouro. Os meninos decidiram ir atrás do tesouro com a ajuda do mapa. Com o tesouro Luís imaginava comprar bastante doces. Renato pensava em comprar um montão de brinquedos. Paulo queria repartir o dinheiro com os pobres. O menino que estaria utilizando o tesouro de forma mais correta seria o Paulo porque ele queria repartir com os pobres. Se eu encontrasse um tesouro, como uma panela de dinheiro, eu iria ajudar os pobres, dar cestas básicas para quem precisa, dar roupas e também ajudar no asilo, nos hospitais, orfanatos e etc. No lugar indicado pelo mapa os meninos encontraram um baú com um bilhete do avô fazendo uma brincadeira com eles. Eu não concordo com a brincadeira feita pelo avô dos meninos. Eles sofreram muito para achar o baú e bem no fim era apenas um bilhete com uma brincadeira malfeita.

Verifica-se que a resposta-final apresentada pelo aluno reconstitui o fluxo textual, evidenciando os processos de identificação de informações textuais, de inferenciação e de interpretação trabalhados ao longo da leitura compartilhada, bem como demonstra a interação realizada com 
o texto e outros sujeitos leitores, visto que retoma a discussão realizada com o professor e com os pares - Cenas 5 e 7 -, confirmando o caráter processual, construtivo da prática de leitura compartilhada.

\section{CONSIDERAC̣ÕES FINAIS}

A partir do desenvolvimento das ações colaborativas, diversos elementos fundamentais da leitura compartilhada puderam ser demarcados, prestando um melhor direcionamento ao ensino dessa prática em SAALP:

- o cerne do trabalho é o processo de leitura, e não o produto desse processo;

- $\quad$ põe-se o texto como um todo de sentidos;

- $\quad$ suscitam-se diversos momentos de interação;

- tem-se como finalidade ensinar a ler e a resolver os problemas de compreensão;

- instruem-se os alunos a chegar ao significado das palavras a partir das pistas que o texto traz;

- delegam-se gradativamente responsabilidades ao aluno, tornando-o um participante na leitura, que apresenta e discute fatos e opiniões;

- desenvolve-se antes da leitura, com atividades de préleitura e a leitura silenciosa; durante a leitura, com explanações colaborativas entre os leitores, mediadas pelo professor; após a leitura, com propostas, orais e escritas, que permitam a expansão dos sentidos textuais;

- trabalham-se as estratégias de leitura: seleção, previsão, inferência e verificação;

- ensina-se o aluno a construir inferências;

- torna-se explícita a dialogicidade na linguagem, recuperando outros dizeres que estão em relação com o texto;

- consente-se que as histórias aflorem em sala de aula;

- permite-se ao leitor chegar ao texto munido de palavras próprias e, a partir do confronto com as palavras alheias, construir novas palavras próprias;

- prolonga-se a cadeia de comunicação discursiva;

- incentiva-se a aprendizagem cooperativa;

- trabalha-se a motivação do leitor e incute no aluno sua 
possibilidade de fornecer contribuições para a discussão;

- fornece-se ao leitor subsídios para uma ação reflexiva e crítica;

- as perguntas de leitura, intrínsecas à leitura compartilhada, refletem as etapas do processo de leitura (MENEGASSI, 2010b), requerendo orientações acerca das respostas dadas pelo aluno;

- a resposta-final sintetiza o trabalho com a leitura compartilhada, favorecendo que o aluno reconstitua o fluxo textual e evidenciando os processos de identificação de informações textuais, de inferenciação e de interpretação trabalhados.

Ao considerarmos esse conjunto de características da leitura compartilhada no trabalho com os alunos da SAALP, entendemos que a prática pedagógica auxilia os alunos na superação das dificuldades de aprendizagem em leitura e no seu desenvolvimento como leitor que toma uma posição em relação ao enunciado do outro, manifestando uma réplica.

\section{REFERÊNCIAS}

ANGELO, C. M. P.; MENEGASSI, R. J. Perguntas de leitura na prática docente em sala de apoio. Rev. bras. linguist. apl. Belo Horizonte, v. 14, n. 3, p. 661-688, set. 2014. Disponível em: <http://www.scielo.br/scielo.php?script=sci_arttext\&pid=S1984-63982014000300008\&lng =en\&nrm=iso $>$. Acesso em: 15 mar. 2015.

BAKHTIN, M. M. (1979). Estética da criação verbal. Tradução do russo por Paulo Bezerra. 4. ed. São Paulo: Martins Fontes, 2003.

; VOLOCHINOV, V. N. (1929). Marxismo e filosofia da linguagem: problemas fundamentais do método sociológico na ciência da linguagem. Tradução do francês por Michel Lahud e Yara Frateschi Vieira. 9. ed. São Paulo: Hucitec, 1999.

BORTONI-RICARDO, S. M. Nós cheguemu na escola, e agora? Sociolinguística e Educação. São Paulo: Parábola Editorial, 2005.

; MACHADO, V. R.; CASTANHEIRA, S. F. Formação do professor como agente letrador. São Paulo: Contexto, 2010.

BRÄKLING, K. L. Leitura colaborativa. In: FRADE, I. C. A. da S. et al. (Org.).Glossário CEALE: termos de alfabetização, leitura e escrita para educadores. Belo Horizonte: Faculdade de Educação, 2014. Disponível em: <http://ceale.fae.ufmg.br/app/webroot/ glossarioceale/verbetes/leitura-colaborativa >. Acesso em: 10 dez. 2014.

BRASIL, Secretaria de Ensino Fundamental. Parâmetros Curriculares Nacionais de Língua Portuguesa, $1^{\circ}$ e $2^{\circ}$ Ciclos do Ensino fundamental. Secretaria de Educação Fundamental. Brasília: MEC/SEF, 1998.

COLOMER, T.; CAMPS, A. Ensinar a ler, ensinar a compreender. Tradução de Fátima Murad. Porto Alegre: Artmed, 2002. 
CURADO, O. H. F. Linguagem dialógica: práticas de leitura e produção de texto. In: OSORIO, E. M. R. (Org.). Mikhail Bakhtin: cultura e vida. São Carlos: Pedro \& João Editores, 2010. p. 141-151.

FONTANINI, A. M. S. M. Discurso e leitura: a prática discursiva da leitura na Sala de Apoio à Aprendizagem de Língua Portuguesa. In: CONGRESSO NACIONAL DE EDUCAÇÃO - EDUCERE. 10. SEMINÁRIO INTERNACIONAL DE REPRESENTAÇÕES SOCIAIS, SUBJETIVIDADE E EDUCAÇÃO - SIRSSE. 1. Anais... Curitiba: PUCPR, 2011. Disponível em: <http://educere.bruc.com.br/CD2011/pdf/4862_2632.pdf>. Acesso em: 13 jun. 2012.

GERALDI, J. W. A aula como acontecimento. São Carlos: Pedro \& João Editores, 2010. IMBERNÓN, F. Formação continuada de professores. Porto Alegre: Artmed, 2010.

LEFFA, V. J. O uso de dicionários on-line na compreensão de textos em língua estrangeira. In: CONGRESSO BRASILEIRO DE LINGUÍSTICA APLICADA, 6, 2001. Belo Horizonte. Anais... Belo Horizonte: UFMG, 2001. Disponível em: <http://www.leffa.pro. br/dicionario.htm>. Acesso em: 21 ago. 2012.

MENEGASSI, R. J. O leitor e o processo de leitura. In: GRECO, E. A.; GUIMARÃES, T. B. (Org.) Leitura: aspectos teóricos e práticos. Maringá: Eduem, 2010a. p. 35-59.

. Perguntas de leitura. In: Menegassi, R. J. (Org.) Leitura e ensino. 2. ed. Maringá: Eduem, 2010b. p. 167-189.

Inferências e produção de sentidos na leitura. In: MENEGASSI, R. J. (Org.).

Leitura, escrita e gramática no ensino fundamental: das teorias às práticas docentes. Maringá: EDUEM, 2010c. p. 67-88.

. Estratégias de leitura. In: MENEGASSI, R. J. (Org.) Leitura e ensino. 2. ed. Maringá: Eduem, 2010d. p. 41-63.

. Avaliação de leitura. In: Menegassi, R. J. (Org.) Leitura e ensino. 2. ed. Maringá: Eduem, 2010e. p.87-106.

PARANÁ. Secretaria de Estado da Educação. Resolução no 208 de 02 de março de 2004. Sala de apoio à aprendizagem. Documento impresso.

PIMENTA, S. G. Pesquisa-ação crítico-colaborativa: construindo seu significado a partir de experiências com a formação docente. Educação e Pesquisa, São Paulo, v. 31, n. 3, p. 521-539, set./dez. 2005.

PIRES, L. M.; JUNGBLUTH, R.; PEIXE, B. C. S. Estudo da eficiência das salas de apoio à aprendizagem no enfrentamento do fracasso escolar na $5^{\mathrm{a}}$ série em 2006 - escolas selecionadas do Núcleo Regional de Educação Área Metropolitana Sul. In: PEIXE, B. C. S. et al. (Org.). Gestão de Políticas Públicas no Paraná: coletânea de Estudos. Curitiba: Editora Progressiva, vol. 1, 516 p., 2008. Disponível em: < http://www.escoladegoverno. pr.gov.br/arquivos/File/gestao_de_politicas_publicas_no_parana_coletanea_de_estudos/ cap_1_educacao/capitulo_1_11.pdf>. Acesso em: 25 fev. 2012.

RODRIGUES, A. Perguntas de leitura e construção de sentidos: experiência com o $6^{\circ}$ ano do Ensino Fundamental. 2013. Dissertação (Mestrado em Letras) - Programa de PósGraduação em Letras, Universidade Estadual de Maringá, Maringá, 2013.

ROJO, R. Letramentos múltiplos, escola e inclusão social. São Paulo: Parábola Editorial, 2009. SOLÉ, I. Estratégias de leitura. Tradução de Claudia Schilling. Porto Alegre: Artmed, 1998. VYGOTSKY, L. S. Obras Escogidas III. Madri: Visor, 2000. 


\section{NOTAS}

${ }^{1}$ Informamos que as abordagens e os instrumentos metodológicos utilizados obedeceram aos procedimentos éticos estabelecidos para a pesquisa científica em Ciências Humanas.

${ }^{2}$ Neste artigo, denominamos Episódios as interações entre pesquisador e professor, nas sessões reflexivas, e Cenas as interações entre professor e alunos, em SAALP.

Submetido: $17 / 04 / 2015$

Aprovado: 10/03/2016

Contato:

Cristiane Malinoski Pianaro Angelo

Rua Ladislau Griczinski, 429, Centro

Irati|UF | Brasil

CEP 84.500-000 